\title{
Forced Freebies: A Note on Partial Deregulation with Pro Bono Supply Requirements*
}

\author{
Maarten Pieter Schinkel ${ }^{\dagger}$ and Jan Tuinstra \\ Revised version: May 2004
}

\begin{abstract}
The liberalization of many former state governed natural monopolies in sectors such as electricity, railroad and telecommunications is done by partial deregulation. Typically, entry is invited into elements of the production chain, yet under strict price and quality controls. This note considers some potential welfare effects of an unconventional type of conditional deregulation, used in the electricity market in Flanders, Belgium, where the utility companies are held to deliver the households they supply a complimentary basic electricity package free of charge. It is shown that, while decreasing the number of new entrants into the liberalized market, such pro bono supply requirements can nevertheless increase net total production. A general condition for a welfare maximizing level of 'forced freebies' is derived.
\end{abstract}

JEL-codes: L51, K23, D43.

Keywords: Liberalization, natural monopoly, regulation, supply requirements.

\section{$1 \quad$ Introduction}

The production of utilities such as gas, electricity and drinking water in many Western European countries used to be concentrated in fully vertically integrated single regional producers with natural monopoly characteristics, that were either privately owned and closely regulated - as in the United States - or ran as a public enterprise - the model of choice in Europe. Since the late 1980's, however, there has been a growing awareness that not all the different functions in the production chain of the utilities need be collected in one integrated monopolist, and that instead substantial benefits can be had from inviting competition in those aspects of production where the economies of scale and scope are small, relative to market demand, so that several firms can be sustained in operation. By decoupling the generation and local retailing of electricity, for example, from its distribution, the natural monopoly characteristics in electricity supply are isolated where they truly exist: in the singular transportation network of power lines. As long as non-discriminatory access to this essential distribution facility is guaranteed by

\footnotetext{
* For comments to earlier versions of this paper, we thank Michael Crew, Wim Driehuis, Ruben Driesen and two anonymous referees. Opinions and errors are ours.

$\dagger$ Department of Economics and ACLE, Universiteit van Amsterdam, Roetersstraat 11, 1018WB Amsterdam, The Netherlands (corresponding author, preferably via e-mail: m.p.schinkel@uva.nl).

* Department of Quantitative Economics and CeNDEF, Universiteit van Amsterdam, The Netherlands. This research was conducted while visiting Universiteit Maastricht. Financial support from METEOR is gratefully acknowledged.
} 
government oversight, market competition amongst a number of retailers can be relied upon to drive down prices and increase productive efficiency. ${ }^{1}$

In the run-up to the 21 st century, many formerly state-controlled utilities have accordingly been gradually liberalized. In the US electricity market, for example, this has led to substantial competition amongst the incumbent firms and new entrants. ${ }^{2}$ Currently, the various member states of the European Union are deregulating and liberalizing their utility markets as well - albeit at somewhat dissimilar paces. Although none of these local markets has settled on an equilibrium with sufficiently many new entries yet, all these transition processes seem well directed. ${ }^{3}$

Obviously, the deregulation of these once dominant producers that, moreover, control the supply of such basic needs as energy and water, is a delicate process that cannot be expected to happen overnight. Maintaining a good quality of service at affordable prices is a serious concern. Therefore, in practice liberalization is a gradual process of partial deregulation, involving quality control and often complicated multi-part price ceilings. Although several scholars have pointed to drawbacks of partial deregulation, advocating a quick - even when possibly dirty - conversion to a fully operational market mechanism, others consider it a useful intermediate policy in transition to a fully free market, for example when there are information asymmetries. ${ }^{4}$

A very special kind of partial price control accompanying the liberalization of entry into the household supply of electricity is seen in Flanders, the Dutch speaking part of Belgium. In its January 2002 decree on the liberalization of the Belgian electricity market, the Flemish government determined that every seller of electricity active on the open market - be it a new entrant or the established incumbent Electrabel - has the public service obligation to supply every household it serves yearly with $100 \mathrm{KWh}$ of electricity per household, plus $100 \mathrm{KWh}$ per person living at the connected address free of charge. ${ }^{5}$

Only on the surplus consumption of electricity above this threshold is the electricity supplier allowed to bill a positive price. For an average Belgian family of four, this $500 \mathrm{KWh}$ of electricity free of charge amounts to between 15 and 20 percent of yearly use. The obligation to supply all households in Flanders this pro bono amount was initially intended to be transitory and in force only until July 2003. Its enforcement period was extended, however. Moreover, the Belgian government followed the Flanders initiative and required a permanent free of charge threshold supply of $556 \mathrm{KWh}$ per household for designated groups of citizens, typically the elderly and the needy, independent of the constitution of the household. ${ }^{6}$ Finally, households that experience

\footnotetext{
${ }^{1} C f$. Newbery (2000), Chapter 5.

${ }^{2}$ Cf. Joskow (1997). A more general overview is provided in Viscusi, Vernon and Harrington (2001), Chapter 12.

${ }^{3}$ Cf. Geradin (2001).

4 Potential dangers of partial deregulation, particularly where it leads to an asymmetric treatment of incumbents and new entrants, are cross-subsidization and so-called 'creamskimming' or 'cherry picking' $c f$. Faulhaber (1975) and Brock and Evans (1983). For a discussion of partial deregulation in natural monopoly transition see Viscusi, Vernon and Harrington (2001), pp.460-4.

${ }^{5}$ See (in Dutch) Beleidsbrief Energie 2002 at www2.vlaanderen.be/ned/sites/beleidsbrieven/Stevaert/energie.pdf.

6 The so-called 'speciaal social tarief' (specific social tariff) that is incorporated in the Sociale Openbare Dienstverpichtingen (Social Public Service Provisions), of July 1, 2003. See www.belgium.fgov.be.
} 
difficulties in paying their electricity bills cannot be disconnected and are guaranteed a continuous minimum supply of six ampere.

These Belgian pro bono supply requirements were originally inspired by social concerns of Flander's socialist minister of energy, Steve Stevaert. The requirement was to correct for Stevaert's concern that it would first and foremost be large buyers and the producers of electricity that would benefit from liberalized access to the market, rather than ordinary consumers. The complimentary electricity was to redistribute part of these alleged asymmetric gains. However desirable these normative considerations - which is a political issue - may be, obliging the utility companies to deliver complimentary basic utility packages makes entry into the newly opened electricity market less attractive. This may, in fact, well lead to a net consumer detriment. After all, the supply of the pro bono electricity package is below costs, thus constituting a loss for each producer that is to be recouped on the sale of electricity over and above the complimentary bundle. This is likely to reduce the number of firms that can be sustained in the market in equilibrium, and hence the level of competition for the provision of electricity. As a result, consumer prices may well be higher, possibly leading to a net increase in total electricity costs for the average Belgian household over and above the total electricity bill without the obligatory free base supply.

When limited to this effect, the Flemish partial liberalization would probably not live up to its social expectations. However, the pro bono supply requirement can have a beneficiary effect on welfare as well. The requirement, namely, introduces an obligatory form of price-discrimination. By inducing the utility companies to supply a fixed amount free of charge, and then determine the rest of their output on the residual demand curve, total individual production typically increases in the size of the pro bono package. The reason for this is that the dilemma of single price-setting firms that marginal revenue decreases in sales for the entire output is partly solved by legal requirement. For a given number of sellers in the market, this has the effect of increasing total output, thus enhancing welfare.

Combined, these two opposing effects raises the question under what conditions the total output reduction effect of the lower number of electricity suppliers in the market in equilibrium is dominated by the increase in supply that each one of them is induced to by the pro bono supply requirement, so that a net increase of total output and hence welfare results. This qualitative issue is considered in this paper, which is organized as follows. The next section illustrates the unambiguous increased output effect from the pro bono supply requirement in a single firm setting. Section 3 then first extends the analysis to a market in which a fixed number of firms is in Cournot competition. It is subsequently established that the total number of firms in the Cournot equilibrium with entry is reduced in the level of pro bono supply. Section 4 weighs the two effects and establishes and optimal level of pro bono supply. Section 5 concludes.

Before proceeding to the analysis, a remark is in order here. Electricity markets and their (partial) liberalization worldwide have been modeled and understood in their intricate detail elsewhere. ${ }^{7}$ It is not our objective to capture such detail here. This note is instead intended to point out a qualitative effect of pro bono supply requirements only. For that, a simple Cournot model suffices. Also, it allows us to abstract from additional regulatory constraints, such as further price controls on the extra-marginal supply.

${ }^{7} C f$. Braeutigam (1997) and Newbery $(1998,2000)$. 
Analyzing the welfare effects of forced freebies in a more complete setup is an interesting topic for further research and a requirement before introducing pro bono supply requirements in any actual market.

\section{$2 \quad$ Single Firm Pro Bono Benefits}

Consider the following stylized model of household electricity supply. A single supplier sells electricity to households in Belgium measured in KWh per year. Demand is given by an inverse demand function $P(Q)$, where $Q$ is the total yearly sales of electricity. It is assumed that demand decreases in price, that is $P^{\prime}(Q)<0$, as long as the price is positive. In the following, we abstract from industrial demand and consider only the generation and retail of electricity for domestic use. A natural monopolist maintains and operates the distribution system, and offers the service of transportation electricity at a fixed fee per unit. As a result, the electricity supplier produces with fixed costs $F \geq 0$ and variable costs $C(Q)$.

Consider first the behavior of the firm in the absence of any regulation in this market. It seeks to maximize profits as follows.

$$
\max _{Q} P(Q) Q-F-C(Q)
$$

so that its choice of output is governed by the first-order condition

$$
P(Q) Q+Q P^{\prime}(Q)=C^{\prime}(Q) \text {. }
$$

Assume that $Q^{0}$ is the unique quantity that maximizes profits.

Next consider the effect of introducing the obligation to produce a free amount of the product $Q_{F}$. This changes the profit maximization problem of the monopolist into

$$
\max _{Q} P(Q)\left(Q-Q_{F}\right)-F-C(Q)
$$

where $Q$ still is total output, now including the amount of electricity supplied for free. Note that although the Belgian pro bono supply requirement that inspired this analysis specifies an amount free of charge per household - so that $Q_{F}$ varies in the total number of households - in the following we abstract from this issue and assume instead that entry into the market requires a fixed pro bono supply. Since electricity is viewed by government as a basic necessity, it seems reasonable to assume that the number of connections is fixed, so that this setup suffices.

Facing the requirement to deliver a basic utility package free of charge, the monopolist's first-order condition for an optimum is

$$
P(Q)+P^{\prime}(Q)\left(Q-Q_{F}\right)=C^{\prime}(Q) \text {. }
$$

Comparing equations (1) and (2), the key thing to notice is that for every level of production marginal revenue increases by the introduction of the pro bono supply requirement. This is immediate from the assumption that $P^{\prime}(Q)<0$ and the observation that $Q-Q_{F}<Q$ for every positive level of $Q_{F}$.

The intuition for the output stimulation effect of the pro bono supply requirement is straightforward as well. It follows from the well-know 'monopolist's dilemma' that for a supplier with some price-setting power that can only set a uniform price for its product 
- that is, that does not have the option of price-discrimination - marginal revenue is a decreasing function of sales. This is so, because supplying one unit of extra output requires lowering the price on all other units as well. The introduction of the obligation to supply some output free of charge partly solves this dilemma for the monopolist. The reason for this is that the price only has to be lowered on the last $Q-Q_{F}$ units, leading to an increase of the marginal revenue for all units over $Q-Q_{F}$ - obviously, all lower output has marginal revenue equal to zero. Moreover, at $Q=Q_{F}$ the marginal revenue for the extra unit of output is exactly equal to the price.

Clearly, when marginal revenue rises and marginal costs are given, profits increase with output. Figure 1 illustrates the effect for the simplest possible case with linear demand and constant marginal costs, leading to average costs $A C(Q)$. The total amount of freebies shifts the demand curve to the left - illustrated as a shift of the price axis to the right. On the residual demand, the monopolist can best offer $Q^{*}$, of which it then sells $Q^{*}-Q_{F}$ at price $P^{*}$. Of the profits thus made on the output actually sold, the area $a b c d$, the loss made on the pro bono supply, the area $d Q_{F} O A C\left(Q^{*}\right)$, is to be subtracted to determine total profits.

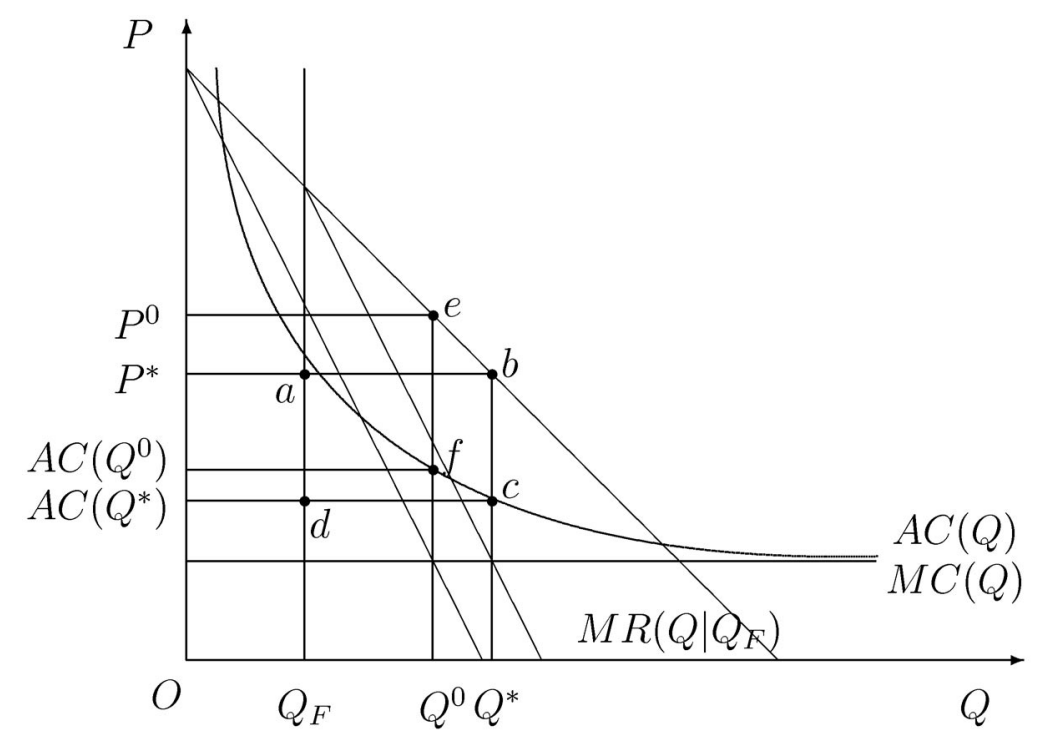

Figure 1. Production increases and profits decrease with 'forced freebies' $Q_{F}$.

Without the pro bono supply, the producer would put $Q^{0}$ on the market and sell it at $P^{0}$, thus making a total profit $P^{0} e f A C\left(Q^{0}\right)$ in the figure. Evidently, the profit without the obligation to deliver part of the complimentary goods is considerably higher than with that requirement. The increase in output pointed at here is immediate from the fact that the marginal revenue curves with and without the pro bono supply requirement are parallel and shifted by $Q_{F}$. This output increasing effect from the pro bono supply requirement also follows unambiguously from a simple comparative statics exercise on equation (2). 


\section{$3 \quad$ Competition and Entry with Pro Bono Supply}

The above monopoly analysis shows the potential of pro bono supply requirements to raise output. The potential detrimental effect of lowering the number of competitors in equilibrium requires a model with several firms and entry, considered in this section. Under the qualifications given in the introduction, let there be $n$ identical electricity retailers in Cournot competition. Let $q_{F}$ denote the size of the complimentary energy package in KWh per year that has to be supplied by each firm. In the Flanders example again, $q_{F}$ would be equal to the total number of households that demand electricity, times the size of the pro bono package per household, divided by the number of firms. For simplicity, however, in the following we consider a single variable $q_{F}$ per firm in the market, the size of which is controlled by the government. Since we consider symmetric Cournot-Nash equilibria only, this assumption is innocuous. Each supplier faces fixed costs $F$, and variable costs given by $C\left(q_{i}\right)$, where $q_{i}$ is individual energy production. Inverse market demand is $P(Q)$ as above, with $Q=\sum_{i=1}^{n} q_{i}$.

Each individual firm determines its supply of electricity in best reply to the supply of the others, by solving

$$
\max _{q_{i}} P(Q)\left(q_{i}-q_{F}\right)-F-C\left(q_{i}\right)
$$

Assume that there exists a symmetric Cournot-Nash equilibrium in pure strategies to this market behavior. For a given number of firms $n$ that each produce $q$, that symmetric equilibrium then is implicitly defined as a solution to the individual first-order condition, i.e.,

$$
P(n q)+P^{\prime}(n q)\left(q-q_{F}\right)-C^{\prime}(q)=0 .
$$

Denote that solution by $q\left(n ; q_{F}\right)$, so that the corresponding aggregate output in the Cournot-Nash equilibrium is $Q\left(n ; q_{F}\right)=n q\left(n ; q_{F}\right)$. We then have the following result.

Proposition 1. For a given number of firms $n$, assume that at the symmetric CournotNash equilibrium the inverse demand function satisfies

$$
P^{\prime}(Q)+P^{\prime \prime}(Q)\left(q-q_{F}\right) \leq 0 .
$$

Then

$$
\frac{d q}{d q_{F}} \geq 0 \text { and } \frac{d Q}{d q_{F}} \geq 0 .
$$

Proof. A simple comparative statics exercise performed on (3) yields

$$
\frac{d q}{d q_{F}}=\frac{P^{\prime}(Q)}{(n+1) P^{\prime}(Q)+n P^{\prime \prime}(Q)\left(q-q_{F}\right)-C^{\prime \prime}(q)},
$$

which will be non-negative if the denominator is negative. Condition (4) is sufficient for $\frac{d q}{d q_{F}} \geq 0$ since 


$$
\begin{aligned}
& (n+1) P^{\prime}(Q)+n P^{\prime \prime}(Q)\left(q-q_{F}\right)-C^{\prime \prime}(q) \\
& =(n-1)\left(P^{\prime}(Q)+P^{\prime \prime}(Q)\left(q-q_{F}\right)\right)+\left[2 P^{\prime}(Q)+P^{\prime \prime}(Q)\left(q-q_{F}\right)-C^{\prime \prime}(q)\right],
\end{aligned}
$$

of which the part in squared brackets is non-positive since it corresponds to the individual firm second-order condition for a maximum. Obviously, $\frac{d Q}{d q_{F}}=n \frac{d q}{d q_{F}} \geq 0$.

Under relatively mild restrictions on the shape of cost and demand functions, which do not go far beyond the conditions necessary for a maximum, market supply for a given number of firms in Cournot competition, therefore, reacts to the pro bono supply requirement similarly to the profit maximizing output of the single monopolist.

Next consider the detrimental effect of the pro bono supply requirement on entry into the market. The equilibrium number of firms is determined endogenously, such that the profits per firm are equal to zero in equilibrium. ${ }^{8}$ That is, the equilibrium number of firms under free entry and exit, $n^{*}=n\left(q_{F}\right)$, is implicitly defined by the following zero profit condition. ${ }^{9}$

$$
\pi\left(n^{*} ; q_{F}\right)=P\left(n q\left(n ; q_{F}\right)\right)\left(q\left(n ; q_{F}\right)-q_{F}\right)-F-C\left(q\left(n ; q_{F}\right)\right)=0 .
$$

The effect on the number of entrants of variations in the amount of electricity that is decreed to be delivered free of charge can then be identified as in the following result.

Proposition 2. Assume that at the symmetric Cournot-Nash equilibrium, the inverse demand function satisfies condition (4). Then $\frac{d n}{d q_{F}} \leq 0$.

Proof. Taking the total differential of (5) and rewriting it, using the symmetric Nashequilibrium condition (3) returns

$$
\frac{d n}{d q_{F}}=-\frac{(n-1) P^{\prime}(Q)\left(q-q_{F}\right) \frac{d q}{d q_{F}}-P(Q)}{P^{\prime}(Q)\left(q-q_{F}\right)\left(q+(n-1) \frac{d q}{d n}\right)} .
$$

This is non-positive since $\frac{d q}{d q_{F}} \geq 0$ and $\frac{d q}{d n} \geq-\frac{q}{n-1}$. That the latter is true is seen by totally differentiating equilibrium condition (3) once more to get

$$
\frac{d q}{d n}=-q \frac{P^{\prime}(Q)+P^{\prime \prime}(Q)\left(q-q_{F}\right)}{(n+1) P^{\prime}(Q)+n P^{\prime \prime}(Q)\left(q-q_{F}\right)-C^{\prime \prime}(q)} .
$$

Using the individual second-order conditions for an optimum, it follows straightforwardly that $\frac{d q}{d n} \geq-\frac{q}{n-1}$.

\footnotetext{
${ }^{8}$ For a sophisticated analysis of entry scenarios for liberalized former exclusive rights markets see Cremer et.al. (2001), which concentrates on the market for postal services.

${ }^{9}$ Note that for simplicity it is assumed that $n$ can be any positive real number, larger than 1 .
} 


\section{$4 \quad$ Optimal Forced Freebies}

Having thus established a potential efficiency decreasing, as well as a welfare increasing effect of the pro bono supply requirement, we are in position to consider the full question what happens to total output $Q$ in the Cournot-Nash equilibrium under free entry when $q_{F}$ increases. That is, we can weigh the two opposite effects that on the one hand the number of firms in equilibrium typically decreases, while on the other the output per individual firm increases. Total output in the Cournot-Nash equilibrium as a function of $q_{F}$ is given as

$$
Q\left(q_{F}\right)=n^{*}\left(q_{F}\right) q\left(n^{*}\left(q_{F}\right) ; q_{F}\right) .
$$

Hence, the effect of changes in $q_{F}$ on total output is governed by

$$
\frac{d Q}{d q_{F}}=\left(q+n^{*} \frac{d q}{d n^{*}}\right) \frac{d n^{*}}{d q_{F}}+n^{*} \frac{d q}{d q_{F}},
$$

which shows that the total quantity effect breaks down in an entry effect, $\left(q+n^{*} \frac{d q}{d n^{*}}\right) \frac{d n^{*}}{d q_{F}}$, which tends to be negative (unless $q$ is very small), and a quantity effect $n^{*} \frac{d q}{d q_{F}}$ that is unambiguously positive.

One way to look at the regulatory issue at hand is as the government facing the following sequential game. In the first stage it decides on the amount of electricity each firm is obliged to provide free of charge, $q_{F}$. In the second stage a Cournot oligopoly game with free entry is played, given $q_{F}$, in which a symmetric Nash equilibrium establishes in $n$ and $q$, determining total output $Q$ as their product. The level of $q_{F}$ thus is the authority's instrument in governing total production in the market. Hence, it should pick $q_{F}$ in the first stage of the game so as to maximize welfare.

Substituting $\frac{Q}{n}-q_{F}$ from the Cournot-Nash equilibrium condition (3), the individual zero profit condition in the free entry equilibrium can be expressed as

$$
\pi(Q, n)=-\frac{P(Q)\left(P(Q)-C^{\prime}(Q / n)\right)}{P^{\prime}(Q)}-F-C\left(\frac{Q}{n}\right)=0 .
$$

Let the relationship between $Q$ and $n$ that is implicitly defined by this zero-profit condition be $Q=g(n)$, and let $n^{*}$ be the value of $n$ for which the maximum level of $Q$ is attained. $Q^{*}=g\left(n^{*}\right)$. The government then can implement the optimal production level by setting the appropriate level of pro bono supply in the first stage of the game as using (3), 


$$
q_{F}^{*}=\frac{Q^{*}}{n^{*}}+\frac{P\left(Q^{*}\right)-C^{\prime}\left(Q^{*} / n^{*}\right)}{P^{\prime}\left(Q^{*}\right)} .
$$

Note that certain constraints apply. Although in principle, the number of firms could approach infinity by letting $q_{F}$ take on negative values, it seems reasonable to require that $q_{F}$, as given by (7), be nonnegative. That is, the pro bono supply should not take the form of a subsidy for the firms. This puts an upper-bound on $n, \bar{n}$. Let the quantity produced when $q_{F}=0$ and therefore, $n=\bar{n}$ be denoted by $Q(0)$. Furthermore, let the individual quantity $\frac{Q(0)}{n}$ be $q(0)$. Then, the following result summarizes the main insights of this paper.

Theorem. Let $q_{F}{ }^{*}$ be the optimal amount of forced freebies. Then:

(i) $q_{F}{ }^{*}=0$ if the individual cost functions satisfy $C^{\prime}(q)>0$ and $C^{\prime \prime}(q) \geq 0$;

(ii) $q_{F}{ }^{*}>0$ if

$$
P(Q(0)) C^{\prime \prime}(q(0))-P^{\prime}(Q(0)) C^{\prime}(q(0))<0 ;
$$

(iii) if an interior solution exists, it satisfies

$$
P\left(Q\left(q_{F}^{*}\right)\right) C^{\prime \prime}\left(q\left(q_{F}^{*}\right)\right)-P^{\prime}\left(Q\left(q_{F}^{*}\right)\right) C^{\prime}\left(q\left(q_{F}^{*}\right)\right)=0 .
$$

Proof. Taking the total differential of (7) and rewriting gives,

$$
\frac{d Q}{d n}=-P^{\prime} \frac{Q}{n^{2}} \frac{P C^{\prime \prime}-P^{\prime} C^{\prime}}{P\left(2\left(P^{\prime}\right)^{2}-P^{\prime \prime}\left(P-C^{\prime}\right)-P^{\prime} C^{\prime \prime}\right)+P^{\prime}\left(1-\frac{1}{n}\right)\left(P C^{\prime \prime}-P^{\prime} C^{\prime}\right)},
$$

where $P$ and its derivatives are evaluated in $Q$ and $C$, and the derivatives of the latter are evaluated in $\frac{Q}{n}$. From the second-order condition that derives from the individual firm's optimization problem it follows that the first expression in the denominator is positive. Therefore, it follows from (8) that a crucial role for the optimal number of firms in the market is played by the sign of

$$
\kappa(Q, n)=P(Q) C^{\prime \prime}\left(\frac{Q}{n}\right)-P^{\prime}(Q) C^{\prime}\left(\frac{Q}{n}\right) .
$$

In particular, if $\kappa(Q, n)>0$, an increase in the number of firms will increase aggregate output. Clearly, this requirement holds globally for all convex cost functions (i.e., cost functions with $\left.C^{\prime \prime}(q)>0\right)$, but also for technologies with constant and positive marginal costs. Moreover, if $\kappa(Q, n)<0$ for pure free entry, that is, at $q_{F}=0$, then this cannot be optimal. Finally, an interior solution has to correspond to $\kappa(Q, n)=0$.

Incidentally, the condition for an interior solution stated in the Theorem allows for an insightful expression, as follows. Let 


$$
\varepsilon_{q P}=\frac{d q}{d P} \frac{P}{Q}
$$

be the price elasticity of residual demand - note that at equilibrium $\frac{d Q}{d P}=\frac{d q}{d P}$ for each firm, since all other firms keep their output constant. Furthermore, let

$$
R(q)=\frac{C^{\prime \prime}(q)}{C^{\prime}(q)} q
$$

be the individual firm's elasticity of marginal cost, which measures the responsiveness of marginal cost to changes in the output. Then result (iii) in the Theorem can be restated as follows.

Corollary. An interior optimal level of forced freebies, $q_{F}{ }^{*}$, satisfies $R(q)=\frac{1}{\varepsilon_{q P}}$.

It is immediate that, since the price elasticity of demand is negative, pro bono supply requirements can only be optimal under increasing returns to scale in production. It is well known that in the single-product context increasing returns to scale are a sufficient condition for sub-additivity of the cost function, which characterizes natural monopolies. ${ }^{10}$

\section{$5 \quad$ Concluding Remarks}

In the process of liberalizing elements of former public utilities, governments have institutionalized various restrictions intended to keep the potential unwanted consequences of imperfect competition at bay, while reaping the benefits of enhanced competition. We have pointed out two qualitative effects of partially deregulating previously restricted market access with price controls that take the form of pro bono supply requirements. These tend to reduce the number of utility companies that can be sustained in equilibrium, yet increase the level of supply of each one of them. Weighing these two opposite effects, we have characterized an optimal level of forced freebies. Interestingly enough, there are conditions under which introducing pro bono supply requirements enhances welfare. We took the special Belgian decree on free basic electricity packages for domestic use as a case in point. Yet, there seems good political rational to indeed offer basic subsistence utility packages for the needy on a wider scale. After all, energy, warmth and water are essential needs for a humane existence. Such measures would need to be taken well-informed and wisely, however, since the quantification of any level of optimal forced freebies in any actual market would be a difficult task. It requires a large amount of information on the part of the government, as well as an understanding of additional regulatory constraints and competitive issues here

${ }^{10}$ Cf. Sharkey (1989). 
ignored. ${ }^{11}$ Yet, when well-applied, forced freebies have the potential to make politically desirable features go hand in hand with good efficiency characteristics.

\section{References}

Braeutigam, R.R., "The Effects of Rivalry with Price Regulation of Electric Power Generation," Journal of Regulatory Economics, 11, 1997, 119-137;

Brock, W. and D. Evans, "Creamskimming," in D. Evans (ed.), Breaking Up Bell, NorthHolland, New York, 1983;

Cremer, H., A. Grimaud, J-P Florens, S. Maray, B. Roy and J. Toledano, "Entry and Competition in the Postal Market: Foundation for the Construction of Entry Scenario's," Journal of Regulatory Economics, 19, 2001, 107-21;

Faulhaber, G., "Cross-Subsidization: Pricing in Public Enterprise," American Economic Review, 65, 1975, 966-77;

Geradin, D. (ed.), The Liberalization of Electricity and Natural Gas in the European Union, Kluwer Law International, Amsterdam, 2001;

Joskow, P.L., "Restructuring, Competition, and Regulatory Reform in the U.S. Electricity Sector," Journal of Economic Perspectives, 11(3), 1997, 119-38;

Newbery, D.M., "Competition, Contracts and Entry in the Electricity Spot Market," RAND Journal of Economics, 29, 1998, 726-49;

Newbery, D.M., Privatisation, Restructuring, and Regulation of Network Utilities, MIT Press, Cambridge, MA, 2000;

Sharkey, W.W., The Theory of Natural Monopoly, Cambridge University Press, Cambridge, 1989;

Viscusi, W.K., J.M. Vernon and J.E. Harrington, Jr., Economics of Regulation and Antitrust, Third Edition, The MIT Press, Cambridge, MA, 2001.

\footnotetext{
${ }^{11}$ Incidentally, these information requirements are substantially lessened when variable costs are constant and equal to zero, so that total costs consist only of (sunk) fixed costs. In that case, market adjustments in terms of entrants and individual supply are such that total market output is constant, irrespective of the required pro bono supply.
} 